\title{
Abstract \\ Ultrasonic assessment of kidney length in a Sri Lankan farming population
}

Nadeeshani $\mathrm{S}^{1^{*}}$, Dassanayake $\mathrm{R}^{1}$, Kodithuwakku $\mathrm{U}^{1}$

${ }^{1}$ Teaching Hospital Anuradhapura, Sri Lanka

\begin{abstract}
Introduction

Normal kidney size has been described as 11 to $14 \mathrm{~cm}$ in standard text books. We studied kidney sizes in adults in a farming village in Anuradhapura. The participants had normal kidney functions, defined as absence of proteinuria and expected glomerular filtration rate above $60 \mathrm{ml} / \mathrm{min} / 1.73 \mathrm{~m}^{2}$.

Methodology

Anonymised data was extracted from results of a chronic kidney disease screening programme held in Sandamaleliya, Thanthirimale, Anuradhapura. Demographic data, creatinine values and ultrasonically measured kidney sizes were documented. Ultrasonography had been performed by the consultant radiologist serving at teaching hospital Anuradhapura. Expected glomerular filtration rate (eGFR) was calculated using the MDRD formula.

Results

Of 285 participants, 56 were excluded due to missing data. Of the others, average age was 44.0 years and $72 \%$ were females. 79.2\% had normal eGFR and their average kidney length was $9.54( \pm 1.63) \mathrm{cm}$, with $9.42( \pm 1.65) \mathrm{cm}$ for right and $9.67( \pm 1.57) \mathrm{cm}$ for left kidneys. Average kidney length for males with normal eGFR was $9.83( \pm 1.49)$ $\mathrm{cm}$ and $9.46( \pm 1.63) \mathrm{cm}$ for females. Average kidney length for participants with normal eGFR and age below 40 years was $9.66( \pm 1.70) \mathrm{cm}$, age 41 to 60 years was $9.47( \pm 1.75) \mathrm{cm}$ and over 60 years was $9.05( \pm 1.50) \mathrm{cm}$. Average kidney length at eGFRs below $60 \mathrm{ml} / 1.73 \mathrm{~m} 2 / \mathrm{min}$ was $8.57( \pm 2.13) \mathrm{cm} .8 .6 \%$ were detected to have renal stones.

Conclusion

Average kidney lengths in this rural farming population were less than generally accepted normal lengths. This finding may be of significance in an area known to have an endemic nephropathy.
\end{abstract}

Key words: Kidney size; Ultrasonography; Renal disease; Anuradhapura

Copyright: (C) 2015 Nadeeshani S et al. This is an open access article distributed under the Creative Commons Attribution License, which permits unrestricted use, distribution, and reproduction in any medium, provided the original work is properly cited.

* Correspondence : shanikanadeeshani85@gmail.com

Cite this abstract as: Nadeeshani S, Dassanayake R, Kodithuwakku U. Ultrasonic Assessment of Kidney Length in a Sri Lankan Farming Population.Anuradhapura Medical Journal 2015;9 (2Supp):S07.

DOI: http://dx.doi.org/10.4038/amj.v9i2Supp.7556 


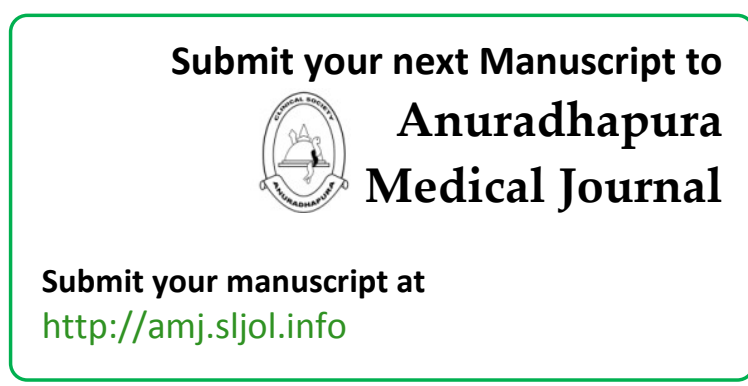

